Vouga, A. (2017). Influências contraculturais no consumo colaborativo: Insights no contexto do Couchsurfing.com. Consumer Behavior Review, 1(2), 73-81.

ISSN: 2526-7884

Editor: Prof. Dr. Marconi Freitas da Costa Email da revista: cbr@ufpe.br
Avaliação: Double blind review

Recebido: 12 de agosto de 2017

Aceito: 20 de novamebro de 2017

\title{
INFLUÊNCIAS CONTRACULTURAIS NO CONSUMO COLABORATIVO: INSIGHTS NO CONTEXTO DO COUCHSURFING.COM
}

\author{
André Vouga
}

André Vouga é Professor Adjunto do Curso de Publicidade e Propaganda da

Universidade Federal de Pernambuco UFPE. E-mail: vouga.andre@gmail.com. 0 autor agracedece aos avaliadores pelos comentários para melhoria do artigo.

\begin{abstract}
Resumo
Este artigo discute parte dos achados de uma imersão netnográfica realizada no Couchsurfing.com, plataforma da web dedicada a trocas de hospitalidade. Nele se mapeiam controvérsias derivadas do choque entre a filosofia de sua constituição, derivada da contracultura, e a práxis ali observada, principalmente quanto: às demandas de densidade dos relacionamentos desenvolvidos, às expectativas de reciprocidade em relação à hospedagem e aos códigos legitimadores da comunidade.

Palavras chave: Cultura do consumo, Redes sociais, Consumo colaborativo.
\end{abstract}

Esta obra está licenciada com uma Licença Creative Commons Atribuição 4.0 Internacional.

\section{INTRODUÇÃO}

0 conceito de consumo colaborativo tem transformado progressivamente diversos setores econômicos, incluindo áreas como: a prestação de serviços, o aluguel de bens, a destinação de usados, o compartilhamento de transportes, entre outros.

Essas transformações se fundamentam no acionamento dos recursos comunicacionais semi-horizontais informatizados de que se dispõe na atualidade. Um ramo onde seu impacto se faz particularmente visível é o de hospitalidade, onde plataformas como
Couchsurfing e Airbnb se configuram progressivamente como alternativas face ao meio hoteleiro, promovendo transformações na visão da hospedagem.

Há, entretanto, diferenças de interesse entre as duas redes. Enquanto a segunda delas se coloca como auxiliar da locação, com uma relação mais objetiva e mediada pelo dinheiro, a primeira é mais focada no intercâmbio entre os envolvidos, numa abordagem que não envolve valores monetários. Aqui nos debruçaremos sobre essas últimas características, indicando como as questões de reciprocidade se tornam problemáticas, em sua complexidade, na medida 
em que não são resolvidas pela mera troca pecuniária.

Para discutir algumas das bases filosóficas que lhes servem de pano de fundo, faremos um breve percurso pelos quadros evolutivos do consumo e do desenvolvimento de certos sistemas contraculturais que lhe impõem questionamentos e, por fim, detalharemos como estes aspectos se conectam com as interações visíveis na rede social estudada.

\section{HIPERCONSUMO}

A reflexão acerca do consumo é fundamental para elucidar conflitos contemporâneos dado que a "cultura do consumo" segue como um dos dominantes da organização social, com seus padrões derivando mudanças de caráter social e econômico: a capilarização mundial da logística, as mudanças nos modos de produção e os reordenamentos nas relações laborais; que alargaram a base de acesso a diversos bens, principalmente nos países centrais. (Slater, 2002). Para Botsman e Rogers (2011), outros elementos deram propulsão ao fenômeno, como a cultura do crédito e as formas da obsolescência programada, tanto física, tecnológica como psicológica.

Lipovetsky (2006) relaciona cronologicamente o incremento do consumo ao fim da Segunda Guerra mundial, época na qual produtos emblemáticos, como os eletrodomésticos, entraram em massa nos lares dos países desenvolvidos. Para ele, a centralidade do individualismo e a insaciável busca pelo novo concretizam uma nova relação entre os sujeitos e os objetos, denominada hiperconsumismo. 0 pensamento de Bauman aponta similitudes em relação ao mesmo contexto, como ele coloca:

Nada no mundo se destina a permanecer, muito menos para sempre [...] nada é necessário de fato, nada é insubstituível [...] tudo deixa a linha de produção com um prazo de validade afixado [...] A modernidade líquida é uma civilização do excesso, da superfluidade, do refugo e da sua remoção. (Bauman, 2005, p. 120).

\section{CONTRACULTURA}

Importa demarcar que, em meio ao mesmo contexto histórico onde se monta uma progressiva centralidade do consumo, também emergiram movimentos com aspectos de reação. $\mathrm{Na}$ linhagem dos movimentos contraculturais, desde o romantismo e a boemia artística européia do século XIX já aparecia uma recusa dos parâmetros materiais burgueses de felicidade.

0 desdobramento desta tradição que emerge no pós-guerra dos EUA, o movimento beat, também carrega consigo essa mesma recusa, com forma própria. De sua maior influência filosófica, o existencialismo francês, herdou um ceticismo diante do projeto moderno de progresso e a recusa de suas formas institucionais, incluindo aquelas que formalizavam as relações de trabalho e de troca econômica.

Talvez pela amálgama com o cadinho cultural estadosunidense, se radicaliza neles a angústia pela liberdade pessoal, tomando uma forma mais diretamente experiencial, com o culto à condição errante como estratégia de desvio das obrigações do enquadramento social. Esses caracteres definem parte das bases de referência para o movimento mochileiro que se estabeleceria a partir do mesmo contexto contracultural (Charters, 1995).

Mais tarde, já na altura da ascensão do hippismo, um segundo elemento se fortalece nos desdobramentos do mesmo sistema contracultural: uma escatologia enamorada das comunidades originárias. Ela aparece em sintonia com a percepção de certas vertentes da sociologia, mais visíveis na leitura de Tonnies (1957), de Durkheim (1978) e de Simmel (1979), que também vê as relações sociais da chamadas comunidades tradicionais de forma idealizada, entendidas como estruturadas de forma mais orgânica. Em contraposição, apontam também perdas nas relações de tipo moderno, entendidas como mecânicas, transitórias, pautadas por interesses específicos e marcadas por valores individualistas.

Para essa linhagem, uma referência central nessa passagem viria da virtual universalização da influência das transações monetárias. 0 dinheiro é entendido como uma espécie de mediador definitivo dos interesses individuais, capaz de permitir a alienação generalizada dos bens e serviços, incluindo possibilidades moralmente questionáveis.

Assim não é de se estranhar que, dentro da linhagem contracultural, tenham sido 
eventualmente revalorizadas relações não centradas nas trocas monetárias. Elas já se demarcavam na percepção da viagem da cultura beat e seguiram pelo espírito comunitário hippie. E importa aqui como perduraram na tradição mochileira que delas derivou. Nesses contextos apareciam mais frequentemente formas que poderiam ser associadas ao circuito dádiva/dívida descrito por Mauss (1974), mais típico de sociedades tradicionais.

\section{COUCHSURFING}

A plataforma Couchsurfing.com nasce, no ano de 2003, em meio a amálgama de diversos elementos derivados destas tradições, conduzidos principalmente pelos desenvolvimentos da cultura mochileira. Mas também com elementos da cultura hacker, embalada na mesma costa oeste norteamericana que deu berço ao beat e ao hippismo.

Principalmente através da exploração das possibilidades de integração comunicacional, franqueadas pela computação, para viabilizar a integração em larga escala da comunidade mochileira, permitindo o casamento entre a demanda dos viajantes $\mathrm{e}$ as ofertas de hospitalidade.

Dessa junção, derivou a proposição de uma rede com foco na qualidade das relações que estabelece, questionando relações formais e voltada para uma abertura à diversidade cultural.

Hoje ela representa a mais bem sucedida e disseminada rede de intercâmbio de hospitalidade gratuita em termos globais. De acordo com os dados fornecidos pelo seu site, atualmente a rede estabelecida possui mais de 7 milhões de membros, dispersos em mais de 100 mil cidades.

Para demarcar a permanência das heranças contraculturais após seu crescimento, um exemplo paradigmático foi o envolvimento generalizado de seus membros na "reconstrução" pela qual seu site precisou passar, no ano de 2006, derivada de uma perda substancial de dados e de recursos de interface advinda de problemas com seus servidores web.

A análise qualitativa das circulações comunicacionais que se dão naquela comunidade também é bastante elucidativa da continuidade da presença dessas dimensões.

\section{ANÁLISE}

Nossa pesquisa se deu a partir da coleta de depoimentos obtida em diferentes instâncias da rede CouchSurfing.com. Estas se mostraram uma fonte bastante rica na medida em que a política da rede incentiva ativamente o uso do sistema de reputação, através das referências, para que haja mais confiança e transparência entre os couchsurfers, incentivando a profundidade das relações pessoais.

Feita no período do dia 18 ao dia 26 de outubro de 2014, a coleta teve uma amostragem de 100 comentários que contemplou a faixa etária de 18 a 56 anos. Em relação à representação por gênero, a amostra continha 49 perfis do sexo feminino ante 47 masculinos.

Inicialmente a interação e a coleta de dados se pautou por intuições trazidas por abordagens prévias da comunidade objeto, que já alertavam para temas frequentes, tais como: as percepções típicas de seus membros, as motivações para viajar, a filosofia de vida. E, ainda, como descrevem suas experiências de viagem e como pensam o encontro com os outros membros.

Os comentários mais relevantes sobre esses temas foram encontrados, em sua maioria, nas seções descritivas dos perfis, tais como: "Opinião sobre o projeto CS", "Como participo do CS" e "Experiência CS". Em menor quantidade, foram coletados comentários de "Descrição Pessoal", "Interesses", "Tipos de pessoas que eu gosto" - seções que compõem o perfil descritivo. E, dentro do total de 100 interações coletadas, a maioria (39) foi proveniente do tópico "Referências". Esta seção se destina às mensagens deixadas por outros membros, que avaliam a experiência vivida com suas contrapartes, recomendando ou não receber ou ser recebido por elas.

\section{O OBTIDO}

Primeiramente, foram selecionados alguns excertos considerados significativos em termos do retrato mais amplo dos ecos culturais localizáveis na comunidade. Um caso exemplar da conexão com as tradições contraculturais veio da recepção negativa do fato do Couchsurfing ter deixado recentemente de ser uma organização sem fins lucrativos, como indicam os casos a seguir: 
Quando era sem fins lucrativos era melhor. (Kecchina, 33 anos - retirado de 'Opinião sobre o projeto Couchsurfing.org'. Disponível em: $<$ https://www.couchsurfing.org/people/kec china/>)

Eu gosto da ideia e parece que funciona muito bem. Parece que o site está ficando muito comercial, só espero que não vá muito longe. (Malte, 27 anos - retirado de 'Opinião sobre o projeto Couchsurfing.org'. Disponível em: $<$ https://www.couchsurfing.org/people/ma ltehorvat/>)

Apesar da amostra só ter contemplado poucos comentários diretos a respeito desse assunto, é possível notar a resistência à referida mudança em detalhes de outras manifestações. O comentário abaixo, apesar de mais positivo, de alguma forma reitera a não aceitação da mudança no formato da organização. E, ainda, demarca a crença existência de uma filosofia anti-capitalista subjacente à visão dos usuários.

Eu realmente acho que isso é uma ÓTIMA forma de não seguir o jeito capitalista de viver... Nós todos podemos compartilhar algo, aprender algo e entender um ao outro, o mundo e nós mesmos um pouco mais quando nos conhecemos assim pessoalmente e compartilhamos nossas casas! (Svirvel, 35 anos - retirado de 'Experiência Couchsurfing'. Disponível em: < https://www.couchsurfing.org/people/svir $\mathrm{vel} />$ )

Já dentro das dimensões de maior interesse para esse estudo, que envolvem as expectativas relativas à hospitalidade em si, é recorrente a afirmação de gostar de conhecer as pessoas que vivem nos lugares por onde se passa, enaltecendo as relações sociais que são criadas durante uma viagem.

Eu amo o espírito do projeto inteiro: Legal, pessoas de cabeça aberta ajudando uma a outra. Para mim, a melhor parte de viajar não é os lugares ou a comida, mas as pessoas que você encontra. Eu trocaria ficar sozinho por uma semana e ver todas as atrações do mundo por uma bebida/conversa calma com uma pessoa interessante. (Niall, 32 anos retirado de 'Opinião sobre o projeto Couchsurfing.org'. Disponível em:
$<$ https://www.couchsurfing.org/people/nd oherty $13 />$ )

Como consequência dos encontros entre as pessoas que a plataforma proporciona, não raro membros citam o surgimento de amizades e enfatizam o troca de experiências e aprendizados.

Através do CS, eu tive a sorte de conhecer tantas pessoas e aprender tantas coisas, rir mais do que eu posso contar, criar amizades e compreender muito, porque as pessoas vão sempre ter muito para compartilhar :) meu mundo não seria o mesmo sem o CS :) (Vlad, 31 anos - retirado de 'Opinião sobre o projeto Couchsurfing.org'. Disponível em: $<$ https://www.couchsurfing.org/people/gol ceavlad/>)

Foi também bastante mencionada a associação da plataforma a um ideal de tolerância, com base na interação entre culturas.

Couchsurfing significa se sentir em casa no mundo. Ele realmente mudou a minha vida, não apenas em relação às viagens, mas na forma que eu interajo com as pessoas e as diferentes culturas. (Mirco, 34 anos retirado de 'Opinião sobre o projeto Couchsurfing.org'. Disponível em: $<$ https://www.couchsurfing.org/profile.htm l?id=4SJO0P0 $>$ )

Há, ainda, discursos divergentes mas complementares, como retratado nos excertos abaixo. Enquanto um usuário fala sobre gostar de conhecer pessoas de diferentes culturas, o outro diz que o Couchsurfing mostra o quanto essas pessoas de diferentes lugares são, na verdade, iguais.

Eu gosto de conhecer pessoas de diferentes culturas, com diferentes contextos e diferentes histórias. Eu gosto de conhecer pessoas de mente aberta, fáceis de conviver e engraçadas que gostam de compartilhar alguma coisa da vida delas. (Jil, 24 anos retirado de 'Como eu participo do CS'. Disponível em: <https://www.couchsurfing.org/people/ wannagototheseaside/>)

O Couchsurfing é um projeto maravilhoso que definitivamente criaria um mundo 
melhor. Ele mostra o quanto as pessoas de vários lugares do mundo são essencialmente iguais. E te permite viajar para todo canto sem sair de casa. (Ana, 31 anos - retirado de 'Opinião sobre o projeto Couchsurfing.org'. Disponível em: $<$ https://www.couchsurfing.org/people /samtree18/>)

A expressão mente aberta é bastante utilizada entre os usuários, tanto para se definir quanto para definir as pessoas que gostaram de conhecer. No entanto, em alguns casos observados, isso acabou sendo alvo de questionamento entre os membros. Em um dos comentários coletados, se renega a facilidade de se autoafirmar como mente aberta apenas na posição de hóspede. Abaixo, vemos uma contraposição dessas ideias.

Eu posso dizer que eu sou um cara mente aberta, com um rico (às vezes distorcido) senso de humor, aberto a novas experiências, ansioso para conhecer novas pessoas e com uma sede ilimitada para ver novos lugares. (Alexandru, 26 anos retirado de 'Descrição Pessoal'. Disponível em:

https://www.couchsurfing.org/people/roca .rolla/>)

Para mim, pessoas que receberam surfers são mais fáceis de serem recebidas [...] Há provavelmente coisas que você não imagina ou reflete até que você esteja na posição de host. Expanda seus horizontes e veja se você é tão "mente aberta e fácil de conviver" quanto você afirma que é :D ha! :) (Zuzana, 32 anos - retirado de 'Experiência Couchsurfing'. Disponível em: <https://www.couchsurfing.org/people/zuz anakulhankova/>)

A grande referência identitária da rede, ser "mente aberta", indica um ideal de pluralidade. Alguns membros explicam que viajar e conhecer pessoas são o meio de compreender a vida e de buscar o autoconhecimento.

Bem, para ser honesto, eu não sei muito sobre a vida ainda, mas espero compreender uma coisa ou outra viajando e conhecendo pessoas novas. (Fabian, 21 anos - retirado de 'Filosofia'. Disponível em: < https://www.couchsurfing.org/people/kata nakarl/>)
Como a maioria das pessoas, eu gosto de vivenciar e tentar coisas novas. Eu acredito que seja bom sair da sua zona de conforto, e participar de coisas que podem não ser fáceis, mas pelas quais você aprende mais sobre você mesmo. (Richard, 25 anos retirado de 'Descrição Pessoal'. Disponível em:

https://www.couchsurfing.org/people/rich ard.bennion/>)

Os usuários também se engajam em contar o que aprenderam com os demais, sobre os lugares e costumes típicos. Na referência abaixo, é interessante também observar que o hospedeiro alega ter redescoberto a própria cidade, por causa dos passeios que teve com o viajante.

Rob foi meu primeiro surfer, no começo eu não sabia o que fazer, mas ele é o tipo de pessoa com quem você logo percebe que gosta de passar tempo junto. Nos passeios com ele, eu redescobri a área onde eu moro, captei outro lado do lugar. Ele pode te contar muito sobre Israel, Letônia e qualquer coisa que você estiver interessado. Tanto que minha família, especialmente minha avó adorou ouvir sobre "Terra Sagrada" :) Eu espero que a gente faça uma viagem pedindo carona algum dia, ou que apenas a gente se encontre de novo e prove algum vinho Tokaj :) (Levente, 18 anos retirado de 'Referências'. Disponível em: $<$ https://www.couchsurfing.org/people/lev i.lakatos $/>$ )

Esse próximo depoimento também traz a discussão do aprendizado, porém em uma perspectiva inusitada: a hóspede promete em uma próxima oportunidade aprender espanhol, a língua nativa do host, pois os dois não falavam uma língua em comum. A comunicação se deu com o auxílio do Google Tradutor e mesmo assim os dois parecem ter se entendido muito bem.

Eu não sei falar espanhol e Jhota não sabe fala Inglês, mas nos comunicamos com o google tradutor, então não há problema para a gente. Ele é uma pessoa muito boa e que se preocupou muito comigo. Ele me mostrou os arredores de Barcelona com sua moto, foi tão legal e até durante a noite, ele quis me levar para ver a fonte mágica, mas estava chovendo por isso não fomos. Eu realmente gostei todo o tempo que passei com você e 
eu espero que se houver uma oportunidade de te ver novamente, eu vou aprender um pouco de espanhol! (Bonnie, 35 anos retirado de 'Referências'. Disponível em: $<$ https://www.couchsurfing.org/people/bo nnie9611/>)

\section{EXPECTATIVAS ESTENTIDAS}

Outra camada de interesse para nossa análise vem do fato de as novas possibilidades de mediação computacional exploradas no site deixarem sua marca modificadora nas formas das relações sociais. Como na tradição, aparecem na plataforma expectativas de reciprocidade em termos dos códigos de visitação e, também, de que os atuais hóspedes se comprometam a receber futuramente. Mas, diferentemente do que se perceberia no contexto de comunidades tradicionais, esses elementos se apresentam de forma recodificada, parcialmente inseridos em sistemas que envolvem contabilidades mais diretas, que recorrem às possibilidades de marcação e concatenação da informação. Justamente os elementos que definem o interesse pelo uso da referida plataforma, dada a possibilidade de antecipar esses dados para possíveis futuros anfitriões ou hóspedes, ainda desconhecidos.

No entanto, se há impactos diretos quando se dá o ordenamento computacional da reputação ainda sobram arestas à sua sombra, que transbordam em outras manifestações dentro da comunidade. Elas envolvem principalmente sutilezas na variação das expectativas de reciprocidade. Um exemplo vem dos comentários feitos por anfitriões após a hospedagem, onde há indicação de expectativas mais complexas que o padrão binário, de aprovação ou não, pedido pelo site.

Um elemento indicativo vem do aparecimento constante da demanda pela densidade das relações, pela qualidade do conhecimento travado entre as pessoas. Indicando o quanto o ideal subjacente ao uso do site é um tanto vago. Um referencial disso vem do fato de alguns usuários explicitarem o descontentamento em receber mensagens sem indícios que o remetente sequer se deu o trabalho de ler seu perfil, exigindo contatos mais personalizados. Abaixo é possível observar um membro sendo mais direto nesse sentido, enquanto outro cria um código descontraído para comprovar que seu perfil foi lido:
Bem, eu acho legal. No entanto poderia ser melhor se mais pessoas estivessem recebendo, e não só surfando. Seria também massa se tivessem menos freeloaders (aproveitadores) mandando mensagens copiadas e coladas sem nenhum perfil. Mas eu acho que essas pessoas nem vão ler meu perfil... então elas não vão ver isso e eu vou continuar a receber esses convites de merda. Eu ainda recebi uma vez um pedido de uma pessoa pedindo para eu 'albergar eles na minha casa'! (Dominique, 28 anos retirado de 'Opinião sobre $\mathrm{o}$ projeto Couchsurfing.org'. Disponível em: $<$ https://www.couchsurfing.org/people/za pou/ $>$ )

Estou interessado em conhecer e eventualmente em hospedar pessoas originais, viajantes de verdade - não mochileiros que apenas querem economizar dinheiro e não estão indo pelo encontro pessoal. [...] Eu rejeito todo convite não pessoal e se você digitar no assunto 'Eu amo Mojitos de Coco e Manga', suas chances de ser aceito são $100 \%$ mais altas. Mostra que você tem bom gosto e que você leu meu perfil, sendo mais provável que vamos nos dar bem e passar um bom tempo juntos. (Dominique, 28 anos - retirado de 'Informações sobre o sofá'. Disponível em: < https://www.couchsurfing.org/people/zapo $\mathrm{u} />$ )

Em meio às queixas acima sobre as mensagens "copiadas e coladas" há outras críticas que aparecem associadas: como a angústia com a sensação de haver mais membros buscando pouso do que hospedando, além de com a percepção de que existem membros que usam a plataforma apenas por economia, não pela qualidade dos encontros e pela densidade das experiências de viajem. Sobre isso, é importante ressaltar que, há uma espécie de entendimento na filosofia originária da rede social, no que diz respeito à conexão entre as pessoas estar pautada por certos valores, que se coloca em tensão no seu processo de expansão.

No entanto, nos perfis observados, as referências às experiências interpessoais foram majoritariamente positivas, umas mais curtas e diretas, outras mais emocionadas e detalhistas. A referência a seguir é um ótimo exemplo, pois logo nas primeiras linhas o usuário explica que uma das maiores vantagens de se usar o site é 
justamente poder conhecer pessoas com as quais, normalmente, não se teria nem contato.

Natalie é a razão pela qual eu gosto tanto do Couchsurfing, porque ele te dá a oportunidade de conhecer pessoas maravilhosas que, de outra forma, você não conheceria! É sempre um prazer estar perto de Natalie e sempre temos os melhores momentos juntas. Ela é doce, engraçada, amigável, uma menina comunicativa. Ela é também uma ótima host, e eu sei que quando eu estiver em Limassol eu posso surfar o seu sofá! Você definitivamente vai encontrá-la em um dos vários eventos que acontecem em Cyprus. Ela é a garota com o maior sorriso! (Maria, 31 anos - retirado de 'Referências'. Disponível em: < https://www.couchsurfing.org/people/mar akicy/>)

É interessante ver como referências como essa são frequentes. Não restam dúvidas que as duas couchsurfers se entenderam muito bem, pois Maria não só faz diversos elogios, como também se sente à vontade em dizer que será bem-vinda em surfar novamente o sofá de Natalie quando tiver oportunidade, o que normalmente não aconteceria com pessoas completamente estranhas entre si.

Seja por compensação ou por gentileza, os surfers geralmente tentam fazer algo para agradar os seus anfitriões, alguma forma retribuir e agradecer pela hospedagem, pelas dicas da cidade etc. No depoimento abaixo, a anfitriã conta como, ao chegar do trabalho, percebeu que as duas pessoas que ela recebeu haviam cozinhado para ela.

Fabian e seu amigo Kevin foram uma maravilha para hospedar! Eu aceitei hospedá-los no último minuto e acabou sendo a melhor decisão. Meus roommates estavam fora no fim de semana então eles puderam viver na minha casa. Fabian é um cara tão legal, e ele e Kevin são rapazes muito doces e respeitáveis. Apesar de estar ocupada no Sábado, eles puderam consertar umas bicicletas minhas exploraram a cidade sozinhos. À noite, eu me surpreendi com uma comida deliciosa que eles fizeram e nós compartilhamos histórias e rimos [...] No geral, foi uma ótima experiência Couchsurfing e eu espero manter o contato com eles para futuras aventuras. Se você tiver a chance de hospedar/viajar/surfar com Fabian, eu definitivamente recomendo!" (Vanda, 25 anos - retirado de 'Referências'. Disponível em: < https://www.couchsurfing.org/people/van dathepanda/>)

Como as pessoas estão sob o mesmo teto, mesmo que por um curto período de tempo, é até normal que certos aspectos da rotina sejam partilhados, como é o caso de uma refeição ou os cuidados da casa. No conteúdo coletado, preparar uma refeição não era exclusividade de um lado só.

Já nessa outra referência, o anfitrião realça o fato da convidada ter ajudado a lavar as louças. Ademais, ela acabou passando mais tempo do que o previsto, o que mostra a flexibilidade das negociações feitas através do Couchsurfing.

[...] Ela deveria ficar por 2 dias e de alguma forma, ela meio que se encaixou entre os móveis e ficou por algumas semanas :-P. Ela me fez rir tanto, porque ela é uma das pessoas mais imprevisíveis que eu conheço. Ela tem milhares de histórias que ela vai adorar te contar ao lado de seu Porto favorito. E todo dia quando eu chegava em casa, as louças tinham sido lavadas :-). É isso que eu chamo de uma boa surfer! Para resumir, a estada dela na minha casa foi ótima. Ela é fácil de conviver e se deu bem com todos onde eu moro. Ela também deixou um desenho lindo, que agora está na parede da minha sala. Te vejo em breve [...] (Dominique, 28 anos - retirado de 'Referências'. Disponível em: $<$ https://www.couchsurfing.org/people/za pou/>)

O desenho feito também é uma alternativa interessante para dizer obrigado, assim como a própria referência escrita pelo anfitrião, que deixou clara a sua satisfação em ter hospedado. Como também pode ser visto acima, no final da mensagem, é comum sinalizar a possibilidade de se ver novamente e de manter contato.

Mas é interessante notar a forma como os mesmos elementos elogiados quando presentes são problematizados em sua ausência. Dentre as referências interpessoais de conteúdo negativo, abaixo temos uma primeira mensagem, deixada pelo anfitrião, e a segunda pela hóspede:

Foi legal conhecer Sona.. mas a única coisa que ela me perguntou foi onde está a 
internet, e que horas ela poderia entrar na casa. Essa foi a extensão de nossas conversas então infelizmente eu não pude conhecer ela melhor. Mas estou feliz que pude ajudar a amiga dela que teve uma experiência ruim. (Dj Justice, 30 anos retirado de 'Referências'. Disponível em: $<$ https://www.couchsurfing.org/people/dj_j ustice/>)

0 comportamento da viajante, a partir da perspectiva do anfitrião, remete à atitude de pessoas que talvez não estão muito habituadas ao sistema e acreditam que o seu funcionamento seja parecido com o da hospedagem em albergues, visto que as preocupações dela eram sobre o acesso à internet e horário para ela entrar na casa.

Foi legal ficar com Tim. Ele me levou para um churrasco no dia 4 de julho e recomendou algumas boates para ir. No entanto, ele passou muito tempo em seu quarto com a porta fechada e música/filme muito alto. Foi uma pena que a gente apenas não tenha encontrado um único assunto em comum e já tivéssemos planos diferentes para o dia. Apesar disso, eu tive uma conversa legal com seu roommate. Mas foi ótimo que minha amiga pode vir e deixar sua mala na casa dele por um dia, isso a ajudou muito. (Sona, 25 anos - retirado de 'Referências'. Disponível em: $<$ https://www.couchsurfing.org/people/so na.happygirl/>)

Após ler o depoimento da hóspede, percebese que houve uma falta de comunicação. Além da possibilidade das duas pessoas apenas não terem de fato nada em comum. Isso mostra que por mais esforços que haja por parte da rede social em engajar seus participantes, às vezes as pessoas simplesmente não vão se entender, por vários dos fatores aos quais estamos expostos em nossas relações interpessoais.

$\mathrm{E}$ as diferenças em termos das sutilezas das expectativas de reciprocidade podem se estender de modo amplo. Por exemplo, dentro da amostragem apareceu a queixa de que há membros utilizando o Couchsurfing como uma plataforma para facilitar encontros amorosos. Em um excerto selecionado para exemplificar a questão, um membro se queixa de que alguns usuários estão se utilizando de parâmetros de avaliação sexual para selecionar quem receber, o que vem dificultando sua procura por anfitriões. Um outro, de forma mais despojada, faz alusão a Star Wars para explicar esses casos:

Eu tenho estado um pouco decepcionado com algumas experiências que eu tive procurando hosts. Me parece que uma grande parte da comunidade está apenas interessada em hospedar pessoas que elas acreditam que possam dormir com elas. Ei, eu gosto de sexo tanto quando os outros caras, mas não é isso o motivo pelo qual eu estou no CS. (Niall, 32 anos - retirado de 'Opinião sobre o projeto Couchsurfing.org'. Disponível em: < https://www.couchsurfing.org/people/ndo herty $13 />$ )

O 'lado negro da força' seria que para algumas pessoas o CS está se tornando um site de relacionamento. No entanto, enquanto você não "entrar no lado negro" você ainda pode ser um CS Jedi ;). (Vlad, 31 anos - retirado de 'Opinião sobre o projeto Couchsurfing.org'. Disponível em: < https://www.couchsurfing.org/people/golc eavlad/>)

As duas citações acima foram feitas por homens, o que denota que não é apenas uma queixa específica do gênero feminino, mas de membros que acreditam que esse não é o objetivo da plataforma e que essa prática pode vir a prejudicar seu bom funcionamento.

\section{CONSIDERAÇÕES FINAIS}

0 percurso pelos excertos obtidos denotou o desenvolvimento corriqueiro de certos temas de importância para a compreensão da comunidade estudada. E, dentre eles se destaca o jogo das expectativas no contexto da hospitalidade entre desconhecidos, no qual mapeamos o quanto um sistema demarcação da reputação relativamente simplificado, típico das interfaces informáticas, é expandido pelos usuários em outros campos de expressão na tentativa de recolocar aspectos mais complexos. Estes envolveram dimensões bem mais sofisticadas das relações de confiança e das expectativas de troca que os desenhistas da rede social puderam prever, provocando formas alternativas do uso da interface disponibilizada, mas ainda assim gerando uma boa carga de malentendidos. 
Mostramos ainda o quanto a rede social estudada serve de elo para condensar agrupamentos com afinidade de perspectivas culturais. E, também, se indicou justamente como se dá a negociação da manutenção dessas crenças, através da construção de códigos de legitimidade e pertencimento dentro da comunidade virtual estudada.

Um dos maiores interesses pressupostos foi mapear o funcionamento de uma rede de trocas que não envolve capital monetário, mas que, ainda assim, é recortada por demandas e expectativas retributivas, cuja complexidade e sutileza abrem margem para tensões permanentes.

Todas essas questões têm como pano de fundo a progressivo aumento da demanda de densidade na experiência do viajar, derivada de ecos contraculturais que seguem influenciando as vertentes principais de nossa cultura e que encontram na comunidade estudada um mecanismo para sua expressão.

Esperamos que o presente trabalho possa se somar a outros, contribuindo para o mapeamento das mudanças com que convivemos nas estruturas do consumo com a expansão de suas formas colaborativas.

\section{REFERÊNCIAS}

Bauman, Zygmunt. (2005). Vidas desperdiçadas. Rio de Janeiro: Jorge Zahar.

Bostman, Rachel \& Rogers, Roo. (2011). O que é meu é seu: Como o consumo colaborativo vai mudar o nosso mundo. Porto Alegre: Bookman.

Charters, Ann. (1992). The portable beat reader. Penguin Books. New York.

Durkheim. E. (1978). Durkheim. In: José Albertino Rodrigues (Org.). São Paulo, Ática.

Lipovetsky, Gilles. (2006). Le bonheur paradoxal essai sur la société d'hyperconsommation. Paris: Gallimard.

Mauss, Marcel. (1974). Ensaio sobre a dádiva. In: Sociologia e Antropologia, vol. 2. EPU, São Paulo.

Simmel, Georg. (1979). A metrópole e a vida mental. In: Velho, Otávio (org.). O fenômeno urbano. Rio de Janeiro, Zahar Ed., p. 11-25

Slater, Dan. (2002). Cultura do consumo \& modernidade. São Paulo: Nobel.

Tonnies, F. (1887). Community and society. East Lansing, MI: Michigan State Univ.Press.

\section{Counter-cultural influences on collaborative consumption: insights in the context of Couchsurfing.com}

\section{Abstract}

This paper discusses the findings of a netnographic immersion held on Couchsurfing.com, web platform dedicated to hospitality exchanges. It is map disputes arising from the clash between the philosophy of its constitution, derived from the counterculture, and the practice observed there, especially regarding: the density demands of developed relationships, the reciprocal expectations for hosting and legitimizing codes of the community.

Key words: consumer culture, social networks sites, collaborative consumption 